\title{
PENGARUH PARTISIPASI ANGGARAN, ASIMETRI INFORMASI, PENEKANAN ANGGARAN, DAN AMBIGUITAS PERAN TERHADAP BUDGETARY SLACK (Organisasi Perangkat Daerah Kota Yogyakarta)
}

\author{
Rani Eka Diansari , Meilia Saraswati
}

Fakultas Bisnis, Universitas PGRI Yogyakarta email: ranieka@upy.ac.id; meiliasaras18@gmail.com

\begin{abstract}
This study aims to examine the effect of budgetary participation, information asymmetry, budget emphasis, and role ambiguity on budgetary slack. This type of research is quantitative research. The population in this study is the Regional Organization of the Government of Yogyakarta City. Sample of research are 58 respondents involved in the preparation of the budget. The sampling selection using purposive sampling method. This research method is a descriptive analysis method with a survey approach. Method of data analysis used in this research is multiple linear regression mode.

In the study, show that budgetary participation have significant positive effect on budgetary slack while information asymmetry, budget emphasis, and role ambiguity have no effect on budgetary slack on the Regional Organizations in the Yogyakarta City Government.

Keywords: Budgetary Participation, Information Asymmetry, Budget Emphasis, Role Ambiguity, Budgetary Slack
\end{abstract}

\section{PENDAHULUAN}

Organisasi harus mempunyai strategi yang baik dalam segala hal, terutama dalam mengontrol sumber daya yang dimilikinya termasuk sumber daya manusia. Seluruh sumber daya yang ada seharusnya digunakan secara efektif dan efisien untuk mendapatkan hasil yang maksimal dan optimal. Dalam operasional organisasi sektor publik, juga terdapat sistem pengendalian manajemen yang berfungsi mengatur sumber daya agar digunakan secara efisien dan efektif untuk mendapatkan hasil yang optimal dan maksimal. Paradigma baru organisasi sektor publik dalam menghadapi pengelolaan sumber daya dengan menggunakan sistem anggaran berbasis kinerja. Sistem anggaran berbasis kinerja ini digunakan dengan memaksimalkan pelayanan publik. Efisiensi dan efektifitas berfokus pada sumber daya untuk tercapainya output yang tinggi (Rahajeng, 2016). Semangat memaksimalkan pelayanan public tersebut seolah digayung bersambut dengan berlakunya UndangUndang Nomor 23 Tahun 2014 Tentang Pemerintahan Daerah yang mencakup tugas dan tanggung jawab dalam pengelolaan keuangan daerah. Dalam hal ini, Penyusunan anggaran merupakan salah satu wewenang pemerintah daerah yang digunakan sebagai 
alat pengendalian dan perencanaan kinerja manajemen jangka pendek maupun jangka panjang (Anthony, 2011). Pemberian wewenang kepada pemerintah daerah dalam penyusunan anggaran dapat memicu individu menciptakan slack anggaran. Slack anggaran disebabkan karena anggaran dan realisasi anggaran terjadi selisih minus atau selisih positif (Rifqi et al., 2017).

Peran partisipatif middle level management dan lower level management dalam dalam proses setting-budgget memberikan peluang untuk menyampaikan aspirasi untuk ke goal budget. Keterlibatan individu dari penyusunan budget participation dapat menimbulkan perilaku positif dengan peningkatan kinerja dan perilaku negative dengan terciptanya budgetary slack (Jermias \& Yigit, 2013). Faktor lain yang menyebabkan terjadinya slack anggaran, adanya asimetri informasi menggambarkan penguasaan informasi yang bisa memicu individu melakukan pemberian informasi bias (Savitri \& Sawitri, 2014). Faktor lain timbulnya budgetary slack adanya tingginya budget emphasis dimana penilaian kinerja individu dilihat dari tercapainya anggaran (Kung et al., 2013). Ketika individu tidak memiliki peran dalam organisasi dan dalam individu bertindak sesuai peran maka akan menimbulkan ambiguitas peran yang memicu terjadinya budgetary slack (Judge \& Robbins, 2015).

Riset terdahulu yang meniliti determinan dari slack anggaran berpendapat budgetary participation, budget emphasis, dan information asymmetry berpengaruh signifikan terhadap slack anggaran (Savitri \& Sawitri, 2014) dan (Tenriwaru, 2015), sedangkan riset yang dilakukan Kusniawati \& Lahaya (2018) dan Safitri, Devi Rasuli, Muhammad (2015) partisipasi anggaran berpengaruh negative namun tidak signifikan terhadap slack anggaran. namun penekanan anggaran dan asimetri informasi berpengaruh positive terhadap slack anggaran. Penelitian Putra \& Mintoyuwono (2019) mengungkapkan bahwa partisipasi anggaran dan penekanan anggaran secara parsial tidak berpengaruh terhadap slack anggaran. Penelitian Aliati Mukaromah (2015) menunjukkan hasil partisipasi anggaran berpengaruh positive terhadap slack anggaran sedangkan asimetri informasi dan ambiguitas peran tidak memiliki pengaruh terhadap slack anggaran.

Fenomena yang terjadi di Pemerintah Kota Yogyakarta terjadi selisih anggaran yang disajikan dalam Tabel 1:

Tabel 1. Anggaran dan Realisasi Pendapatan Anggaran Daerah Pada Pemerintah Kota Yogyakarta Tahun 2016-2018

\begin{tabular}{ll}
\hline Keterangan & Tahun \\
\cline { 2 - 2 } & 2016 \\
\hline Anggaran & $1.595 .318 .043 .914,00$ \\
\hline Realisasi & $1.577 .679 .933 .045,20$ \\
\hline Selisih \% & $99 \%$ \\
\hline Keterangan & Tahun \\
\cline { 2 - 2 } & 2017 \\
\hline Anggaran & $1.586 .451 .305 .811,00$ \\
\hline Realisasi & $1.659 .277 .141 .816,66$ \\
\hline Selisih \% & $105 \%$ \\
\hline Keterangan & Tahun \\
\cline { 2 - 2 } & 2018 \\
\hline Anggaran & $1.698 .804 .931 .325,00$ \\
\hline Realisasi & $1.736 .919 .997 .852,52$ \\
\hline Selisih \% & $102 \%$ \\
\hline \multicolumn{2}{c}{ sumber: bpkad.jogjakota.go.id }
\end{tabular}

menunjukkan bahwa kinerja Organisasi Perangkat Daerah pada Kota Yogyakarta kurang optimal, ditunjukkan pada penetapan anggaran dan realisasi anggaran tahun 20162018 di OPD pada Pemerintah Kota Yogyakarta terjadi budgetary slack dimana selisih kurang dan selisih lebih tinggi dari target pendapatan anggaran. Beberapa penelitian terdahulu menunjukkan hasil yang tidak consistent dan fenomena yang terjadi pada Pemerintahan Kota Yogyakarta, maka penelitian ini dilakukan untuk mengetahui apakah terjadinya kesejangan anggaran dipengaruhi empat factor keterlibatan individu, pemberian informasi bias, budget emphasis, dan ambiguitas peran.

\section{KAJIAN TEORI}

a. Teory Agensi

Teori keagenan menjelaskan pendelegasian wewenang principal kepada agent untuk melaksanakan tugas dan tanggungjawab manajemen. Teori agen dalam praktik kesejangan anggaran dipengaruhi adanya conflict kepentingan 
antara principal dan agent terkait pencapaian target anggaran (Lubis, 2017).

b. Budgetary slack

Slack anggaran terjadi karena adanya selisih jumlah anggaran dan realisasi anggaran organisasi. Anggaran memicu perilaku individu melakukan slack anggaran untuk ke goal budget (Suartana, 2010: 138). Menurut Horngren (2014) budgetary slack merupakan mengurangi perolehan pendapatan dan melebihkan anggaran biaya untuk mempermudah pencapaian target anggaran.

c. Partisipasi anggaran

Menurut Lubis (2017) participation dalam proses perancangan anggaran adalah proses penetapan keputusan bersama dalam proses manajemen. Budget partisipasion mendorong adanya kekuasaan yang menimbulkan perilaku disfungsional individu terhadap organisasi. Tiga potensi masalah partisipatif yaitu tinggi atau rendah penetapan anggaran, kelonggaran anggaran, dan partisipasi semu (Hansen \& Mowen, 2009). Penelitian terdahulu menjelaskan adanya penyalahgunaan wewenang terhadap penetapan anggaran guna mempermudah targat pencapaian angaran dimana adanya kesempatan individu untuk melakukan budgetary slack demi kepentingan pribadi (Panjaitan, dkk 2019). Berdasarkan penjelasan yang diuraikan diatas peneliti berkeyakinan untuk membangun hipotesa: $\boldsymbol{H}_{\mathbf{1}}=$ Partisipasi anggaran berpengaruh terhadap budgetary slack

d. Asimetri Informasi

Menurut Lubis (2017) timbulnya asimetri informasi terjadi karena agent lebih memahami informasi lebih yang menyebabkan atasan tidak mampu untuk menentukan apakah bawahan melakukan pekerjaan dengan benar secara optimal. Asimetri informasi dianggap sebagai faktor timbulnya budgetary slack dikarenakan adanya pemanfaatan informasi untuk menciptakan kelonggaran anggaran (Fanani \& Saudale, 2019). Penelitian terdahulu menjelaskan tingginya information asymmetry dalam penyusunan anggaran akan menyebabkan tingginya budgetary slack pada organisasi (Dianthi \& Wirakusuma, 2017). Berdasarkan penjelasan diatas peneliti berkeyakinan untuk membangun hipotesa: $\boldsymbol{H}_{\mathbf{2}}=$ Asimetri informasi berpengaruh terhadap budgetary slack

e. Penekanan Anggaran

Manurut Suartana (2010) budget emphasis dapat menyebabkan dampak langsung terhadap perilaku individu bekerja dibawah tekanan. Budget emphasis dapat membuat individu malakukan slack terhadap anggaran dengan menetapkan anggaran yang mudah dicapai. Kesenjangan anggaran menjadi tinggi karena penilaian kinerja agent bergantung pada tercapainya anggaran yang ditetapkan (Putri, dkk. 2012). Penelitian terdahulu menjalaskan Budget emphasis menjadi management control untuk memenuhi tercapainya target anggaran yang dapat menyebabkan slack anggaran (Fadhli \& Indriani, 2019). Berdasarkan penjelasan diatas peneliti berkeyakinan untuk membangun hipotesa:

$\boldsymbol{H}_{\mathbf{3}}=$ Penekanan anggaran berpengaruh terhadap budgetary slack

f. Ambiguitas peran

Role ambiguity merupakan ketidaksesuaian individu dalam menerapkan perannya dalam organisasi secara optimal dengan begitu pekerjaan yang dikerjaan individu menjadi kurang efektif (Ana \& Ratnadi, 2016). Robbins \& Judge (2017) menyatakan ambiguitas peran terjadi ketika role expectation tidak secara jelas dimengerti, maka menyebabkan konflik peran yang dapat mempengaruhi terjadinya budgetary slack. Penelitian terdahulu menjelaskan tingginya Role ambiguity individu dalam organisasi maka akan menyebabkan tinnginya slack anggaran (Ana \& Ratnadi, 2016). Berdasarkan penjelasan diatas peneliti berkeyakinan untuk membangun hipotesa:

$\boldsymbol{H}_{\mathbf{4}}=$ Ambiguitas Peran berpengaruh terhadap budgetary slack

PENELITIAN TERDAHULU 
Skema hubungan antara variable independen dengan variable dependen atau kerangka berfikir riset ini dapat disajikan dalam gambar sebagai berikut

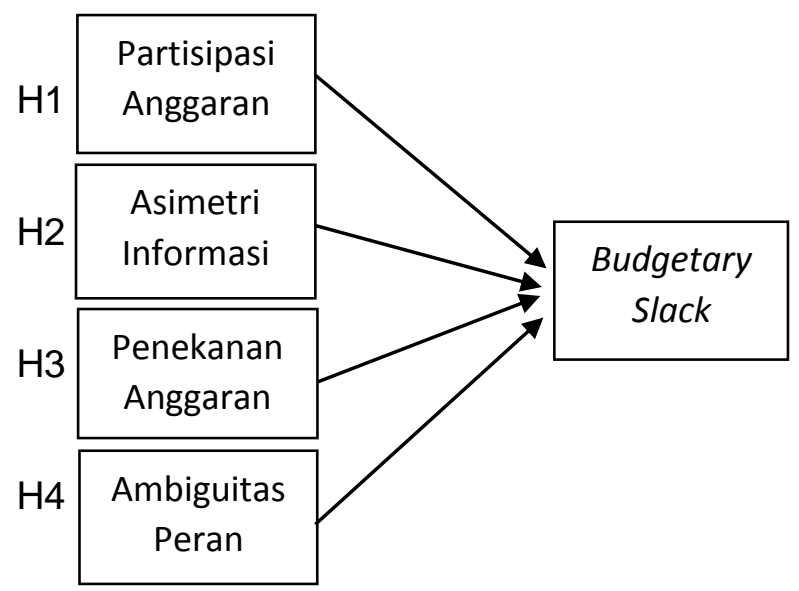

Gambar 1. Kerangka Berfikir

\section{METODE}

\section{Objek dan Sampel Penelitian}

Populasi pada penelitian ini adalah OPD Kota Yogyakarta pada instansi Dinas dan Badan. teknik pengambilan sampel adalah purposive sampling dengan kriteria responden pejabat dan staff yang terlibat dalam proses penyusuanan, pelaksanaan, dan pertanggungjawaban anggaran pada instansi badan dan dinas yang tergabung dalam OPD Kota Yogyakarta. Penelitian ini merupakan data kuantitatif dengan metode pengumpulan data menggunakan metode survey. Peneliti menyebar 70 kuesioner yang kembali dan dapat diolah adalah 58 kuesioner, serta sisanya tidak kembali.

\section{Variable Penelitian \\ Budgetary Slack}

Peneliti mengukur budgetary slack menggunakan indikator yang disarankan oleh Dunk (1993) dengan indikator peningkatan produktivitas, pencapaian anggaran, pemonitor biaya karenya adanya cut-off anggaran, perbaikan anggaran, efisiensi anggaran, dan penyebab ketidaktercapaian anggaran dan realisasi.

\section{Partisipasi Anggaran}

Peneliti mengukur partisipasi anggaran menggunakan variabel yang disusun oleh Akhmad Azmi Basyir (2016) dengan indikator penyusunan anggaran, kemampuan beropini, kuantitas pemberian pemikiran, pengaruh dalam penyusunan anggaran, pengaruh principal kepada agent untuk berpendapat, serta kontribusi pada penyusunan anggaran.

\section{Asimetri Informasi}

Peneliti mengukur asimetri informasi menggunakan variabel yang disusun oleh Aliati Mukaromah (2015) dengan indikator informasi yang dimiliki agent dibandingkan principal, hubungan input-output, kinerja potensial, teknis pekerjaan, dapat menilai dampak potensial, dan pencapaian kegiatan.

\section{Penekanan Anggaran}

Peneliti mengukur penekanan anggaran menggunakan variable yang disusun oleh Anggasta \& Murtini (2014) dengan indikator alat pengendali, pencapaian target anggaran, peningkatan kinerja karena anggaran, reward, dan pemberian kompensasi.

\section{Ambiguitas Peran}

Peneliti mengukur ambiguitas peran menggunakan variable yang disusun oleh Ardila (2013) dengan indikator kejelasan wewenang pada instansi, harapan instansi, keyakinan wewenang, kejelasan pekerjaan, mempunyai tujuan yang jelas terhadap pekerjaan, dan membagi waktu dalam bekerja.

\section{HASIL DAN PEMBAHASAN}

Peneliti melakukan pengumpulan data responden selama kurang lebih 1 (satu) bulan. Data dalam penelitian ini diperoleh peneliti dari responden dengan membagikan kuesioner. Statistik kuesioner terlihat pada Tabel 2 berikut.

Tabel 2. Statistik Kuesioner

\begin{tabular}{|l|l|l|}
\hline Keterangan & Jumlah & Presentase \\
\hline Kuesioner yang disebar & 70 & $100 \%$ \\
\hline $\begin{array}{l}\text { Kuesiner yang tidak } \\
\text { kembali }\end{array}$ & 12 & $17 \%$ \\
\hline Kuesioner yang diolah & 58 & $83 \%$ \\
\hline
\end{tabular}

Sumber: Data primer diolah, 2020

Tabel 2 menunjukkan sebaran kuesioner dari 70 (tujuh puluh) buah yang disebar, 12 (dua belas) buah tidak kembali dan 56 (lima puluh enam) buah kuesioner dapat diolah untuk dianalisis. Karakteristik responden yang menjadi sampel ditunjukkan pada Tabel 3 berikut: 
Tabel 3. Demografi Responden

\begin{tabular}{|c|c|c|}
\hline Karakteristik & $\begin{array}{l}\text { Freku } \\
\text { ensi }\end{array}$ & $\begin{array}{l}\text { Prese } \\
\text { ntase }\end{array}$ \\
\hline \multicolumn{3}{|l|}{ Jenis Kelamin } \\
\hline Laki-laki & 20 & $34 \%$ \\
\hline Perempuan & 38 & $66 \%$ \\
\hline \multicolumn{3}{|l|}{ Usia } \\
\hline 25 - 30 Tahun & 2 & $3 \%$ \\
\hline 31 - 40 Tahun & 15 & $26 \%$ \\
\hline 41 - 50 Tahun & 22 & $38 \%$ \\
\hline 51 - 60 Tahun & 19 & $33 \%$ \\
\hline \multicolumn{3}{|l|}{ Tingkat pendidikan } \\
\hline S2 & 20 & $34 \%$ \\
\hline S1 & 30 & $52 \%$ \\
\hline D3 & 5 & $9 \%$ \\
\hline SMA & 2 & $3 \%$ \\
\hline SMK & 1 & $2 \%$ \\
\hline \multicolumn{3}{|l|}{ Jabatan } \\
\hline Kabid Keuangan & 1 & $2 \%$ \\
\hline Kabid Anggaran & 1 & $2 \%$ \\
\hline Kabid Pelaporan & 2 & $3 \%$ \\
\hline \multirow{2}{*}{$\begin{array}{l}\text { Kasubbag Keuangan } \\
\text { Kasubbag Pelaporan dan } \\
\text { Keuangan }\end{array}$} & 11 & $19 \%$ \\
\hline & 5 & $9 \%$ \\
\hline & 10 & $17 \%$ \\
\hline Kasubbag Umum \& & \multicolumn{2}{|c|}{ Kepegawaian $\quad 17$} \\
\hline \multicolumn{3}{|c|}{ Kasubbid Belanja Non } \\
\hline Gaji & 1 & $2 \%$ \\
\hline \multicolumn{2}{|l|}{ Bendahara } & \\
\hline Kepala Sekretariat & 1 & $2 \%$ \\
\hline Staff Bagian Keuangan & 3 & Staff Bagian Keuangan \\
\hline \multicolumn{3}{|l|}{$\begin{array}{l}\text { Staff Bagian Umum \& } \\
\text { Kepegawaian }\end{array}$} \\
\hline \multicolumn{3}{|l|}{ Staff Tata Usaha } \\
\hline \\
\hline & & \\
\hline \multicolumn{3}{|l|}{$\begin{array}{l}\text { Perencanaan, Evaluası \& } \\
\text { Pelaporan Tenaga Teknis }\end{array}$} \\
\hline \multicolumn{3}{|l|}{$\begin{array}{l}\text { Bag. Umum \& } \\
\text { Kepegawaian }\end{array}$} \\
\hline \multicolumn{3}{|l|}{ Lama bekerja } \\
\hline - 1 - 10 Tahun & 6 & $10 \%$ \\
\hline - 11 - 20 Tahun & 18 & $31 \%$ \\
\hline - 21 - 30 Tahun & 30 & $52 \%$ \\
\hline$->30$ Tahun & 4 & $7 \%$ \\
\hline
\end{tabular}

Sumber: Data primer diolah, 2020

Tabel 3 menunjukkan gambaran terperinci mengenai responden dalam riset ini menjadi kelompok bagian yaitu gender, umur, tingkat pendidikanm jabatan, dan masa karja. Berdasarkan tabel 3 dapat disimpulkan bahwa mayoritas responden berjenis kelamin perempuan sebesar $66 \%$, rata-rata berusia $41-$
50 tahun sebesar 38\%, tingkat pendidikan sarjana (S1), dengan lama bekerja diatas 20 (dua puluh) tahun.

Penelitian ini menggunakan model regresi linear berganda maka data harus di uji validitas dan reliabilitasnya sebagai berikut:

Tabel 4. Hasil Uji Validitas

\begin{tabular}{|c|c|c|c|c|}
\hline Variabel & Butir & $\begin{array}{l}\text { Korela } \\
\text { si }\end{array}$ & Sig. & $\begin{array}{l}\text { Ketera } \\
\text { ngan }\end{array}$ \\
\hline \multirow{5}{*}{$\begin{array}{l}\text { Budgetary } \\
\text { Slack }(\mathrm{Y})\end{array}$} & Y1 & 0,695 & 0,000 & Valid \\
\hline & $\mathrm{Y} 2$ & 0,625 & 0,000 & Valid \\
\hline & Y3 & 0,579 & 0,000 & Valid \\
\hline & Y4 & 0,649 & 0,000 & Valid \\
\hline & Y5 & 0,387 & 0,003 & Valid \\
\hline \multirow{6}{*}{$\begin{array}{l}\text { Partisipasi } \\
\text { anggaran } \\
\text { (X1) }\end{array}$} & $\mathrm{X} 1.1$ & 0,824 & 0,000 & Valid \\
\hline & $\mathrm{X} 1.2$ & 0,745 & 0,000 & Valid \\
\hline & $\mathrm{X} 1.3$ & 0,888 & 0,000 & Valid \\
\hline & X1.4 & 0,871 & 0,000 & Valid \\
\hline & X1.5 & 0,864 & 0,000 & Valid \\
\hline & X1.6 & 0,906 & 0,000 & Valid \\
\hline \multirow{6}{*}{$\begin{array}{l}\text { Asimetri } \\
\text { Informasi } \\
\text { (X2) }\end{array}$} & X3.1 & 0,815 & 0,000 & Valid \\
\hline & X3.2 & 0,844 & 0,000 & Valid \\
\hline & X3.3 & 0,886 & 0,000 & Valid \\
\hline & X3.4 & 0,829 & 0,000 & Valid \\
\hline & X3.5 & 0,841 & 0,000 & Valid \\
\hline & X3.6 & 0,862 & 0,000 & Valid \\
\hline \multirow{6}{*}{$\begin{array}{l}\text { Penekanan } \\
\text { Anggaran } \\
\text { (X3) }\end{array}$} & X2.1 & 0,791 & 0,000 & Valid \\
\hline & $\mathrm{X} 2.2$ & 0,830 & 0,000 & Valid \\
\hline & X2.3 & 0,771 & 0,000 & Valid \\
\hline & X2.4 & 0,775 & 0,000 & Valid \\
\hline & $\mathrm{X} 2.5$ & 0,696 & 0,000 & Valid \\
\hline & X2.6 & 0,558 & 0,000 & Valid \\
\hline \multirow{6}{*}{$\begin{array}{l}\text { Ambiguitas } \\
\text { Peran (X4) }\end{array}$} & $\mathrm{X} 4.1$ & 0,830 & 0,000 & Valid \\
\hline & $\times 4.2$ & 0,867 & 0,000 & Valid \\
\hline & $\mathrm{X} 4.3$ & 0,788 & 0,000 & Valid \\
\hline & X4.4 & 0,842 & 0,000 & Valid \\
\hline & X4.5 & 0,890 & 0,000 & Valid \\
\hline & X4.6 & 0,686 & 0,000 & Valid \\
\hline
\end{tabular}

Sumber: Data primer diolah, 2020

Tabel 5. Hasil Uji Reliabilitas

\begin{tabular}{|l|c|c|l|}
\hline \multicolumn{1}{|c|}{ Variabel } & A & $\begin{array}{c}\mathrm{N} \text { of } \\
\text { Items }\end{array}$ & \multicolumn{1}{|c|}{ Keterangan } \\
\hline Budgetary & 0,533 & 5 & Kurang reliabel \\
\hline Partisipasi & 0,922 & 6 & Reliabel tinggi \\
\hline Asimetri & 0,920 & 6 & Reliabel tinggi \\
\hline Penekanan & 0,826 & 6 & Reliabel tinggi \\
\hline Ambiguitas & 0,893 & 6 & Reliabel tinggi \\
\hline
\end{tabular}

Sumber: Data primer diolah, 2020

Berdasarkan tabel 4 menunjukkan bahwa semua pertanyaan dalam kuesioner yang dibagikan kepada responden dinyatakan valid. Tabel 5 menunjukkan variable partisipasi anggaran, asimetri informasi, penekanan anggaran dan ambiguitas peran memiliki reliabilitas tinggi sedangkan 
variable budgetary slack menunjukkan hasil kurang reliabel.

Hasil dari hipotesis dapat dilihat pada tabel 5 berikut:

Teble 5. Hasil Uji R², Uji Regresi Linear, Uji F dan Uji t

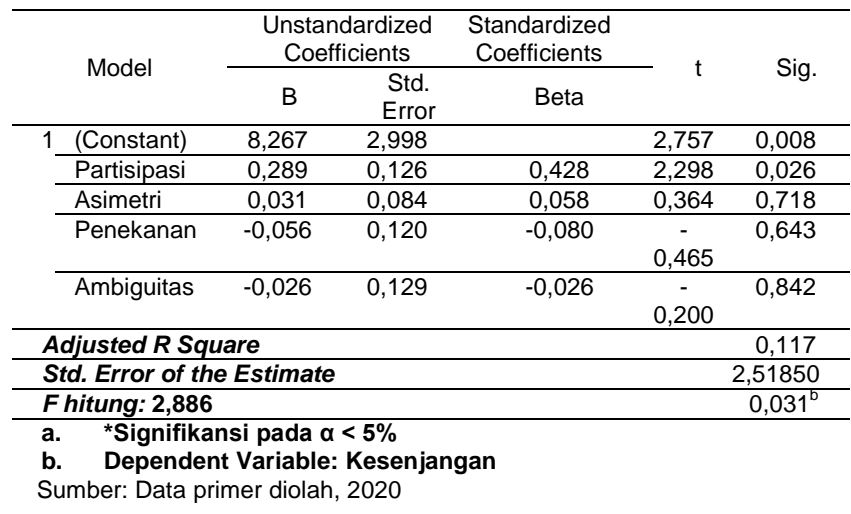

\section{Analisis Uji Regresi Linear}

Jika angka-angka yang disajikan pada tabel 5 (lima) dimasukkan dalam model regresi linear

$$
\begin{gathered}
Y=8,267+0,289_{x_{1}}+0,031_{x_{2}}-0,056_{x_{3}} \\
-0,026_{x_{4}}+\mathrm{e}
\end{gathered}
$$

Model diatas diartikan:

1. Jika angka Constant 8,267 yang merepresentasikan determinan budgetary slack tetap pada OPD di Pemerintah Kota Yogyakarta sebesar 8,267.

2. Angka $\beta 1=0,289$ menyatakan variable pertama kearah positif yang artinya jika variable pertama terjadi peningkatan 1 (satu) akan mempengaruhi budgetary slack sebesar 0,289.

3. Angka $\beta 2=0,031$ menyatakan variable kedua kearah positif, yang artinya sehingga jika variable kedua terjadi peningkatan 1 (satu) akan mempengaruhi budgetary slack sebesar 0,031.

4. Angka $\beta 3=-0,056$ menyatakan variable ketiga kearah negatif. Yang artinya sehingga jika variable ketiga terjadi penurunan 1 (satu) akan mempengaruhi budgetary slack sebesar 0,056.

5. Angka $\beta 4=-0,026$ menyatakan variable keempat kearah negatif. Sehingga jika variable keempat terjadi penurunan 1 (satu) akan mempengaruhi budgetary slack sebesar 0,026.
Analisis Uji ( $\left.\mathbf{R}^{2}\right)$

Berdasarkan tabel 5 dapat disimpulkan bahwa variable yang diajukan oleh peneliti pada OPD di Pemerintah Kota Yogyakarta hanya menduduki mayoritas sebesar $11,7 \%$, sedangkan $88,3 \%$ dipengaruhi oleh variable lain yang tidak ada dalam riset ini.

\section{Analisis Uji F}

Berdasarkan tabel 5 menunjukkan bahwa 2,886 F value $0,031<0,05$, maka dapat disimpulkan bahwa determinan slack anggaran secara bersama-sama mempengaruhi kesenjangan anggaran.

\section{Analisis Uji t}

Uji siginifikansi parameter individual untuk menguji pengaruh masingmasing determinan slack anggaran. Dengan signifikansi $\quad 0,026<0,05$ maka hipotesis pertama terdukung dengan kata lain bahwa partisipasi anggaran berpengaruh terhadap budgetary slack. Variable kedua dengan sigifikansi 0,718>0,05, maka dugaan hipotesis kedua tidak didukung dengan kata lain asimetri informasi tidak berpengaruh terhadap budgetary slack. Variable ketiga dengan signifikansi 0,643, maka dugaan hipotesis ketiga tidak didukung dengan kata lain penekanan anggaran tidak bepengaruh terhadap budgetary slack. Variable keempat dengan signifikansi 0,842>0,05 maka dugaan hipotesis keempat tidak didukung dengan kata lain ambiguitas peran tidak berpengaruh terhadap budgetary slack.

Pembahasan

Hipotesis pertama yang terdukung mengindikasikan bahwa semakin tinggi tingkat partisipasi anggaran maka akan mempengaruhi pengaruh terhadap kesenjangan anggaran. Penelitian sebelumnya menyatakan hasil yang sama adalah Savitri \& Sawitri (2014) dan Tenriwaru (2015) dimana partisipasi anggaran memiliki pengaruh terhadap budgetary slack. Menurut teori kegenan, adanya hubungan antara principal dan agent akan menciptakan budgetary slack dengan menetapkan anggaran yang rendah pada pendapatan dan biaya yang tinggi untuk memudahkan pencapaian target anggaran Suartana (2010). 
Hipotesis kedua yang tidak didukung mengindikasikan bahwa asimetri informasi tidak berpengaruh tehadap budgetary slack. Penelitian sebelumnya menyatakan hasil yang sama adalah (Bangun \& Andani, 2012) dan Aliati Mukaromah (2015) menunjukkan hasil bahwa asimetri informasi tidak berpengaruh terhadap slack anggaran. Asimetri informasi itu mungkin terjadi karena pemahaman penerimaan informasi antar individu berbeda sehingga semestimya ada peraturan organisasi pemerintah yang menjelasan mengenai tugas dan kewajiban meliputi informasi yang diterima agent harus dilaporkan ke principal agar tidak menjadikan perbedaan informasi yang diterima.

Hipotesis ketiga yang tidak didukung mengindikasikan bahwa penekanan anggaran tidak berpengaruh terhadap budgetary slack. Penelitian sebelumnya menyatakan hasil yang sama adalah Putra \& Mintoyuwono (2019) menunjukkan hasil budget emphasis tidak berpengaruh terhadap budgetary slack. Dalam hal ini dapat didijelaskan bahwa anggaran tidak menjadikan satu-satunya alat penilaian kinerja sehingga agent tidak mengejar capaian target anggaran yang ditetapkan.

Hipotesis keempat yang tidak didukung mengindikasikan bahwa ambiguitas peran tidak berpengaruh terhadap budgetary slack. Penelitian sebelumnya menunjukkan hasil yang sama adalah Aliati Mukaromah (2015) menunjukkan ambiguitas peran tidak berpengaruh terhadap budgetary slack. Gusti \& Sofyan (2019) menyatakan kejelasan individu dalam mengetahui peran dan kejelasan pekerjaan akan menjadikan rencana dan tujuan pekerjaan dapat terlasana.

\section{KESIMPULAN DAN SARAN}

Simpulan yang diberikan:

1. Penelitian yang dihipotesiskan dalam riset ini menunjukkan hasil minoritas sebesar $11,7 \%$, sedangkan sisanya $88,3 \%$ faktor yang tidak dimasukkan dalam riset ini.

2. Keseluruhan determinan berpengaruh terhadap timbulnya budgetary slack pada OPD di Pemerintah Kota Yogyakarta.
3. Sedangkan secara parsial, partisipasi anggaran memiliki pengaruh terhadap budgetary slack namun asimetri informasi, penekanan anggaran, dan ambiguitas peran tidak berpengaruh terhadap budgetary slack pada OPD di Kota Yogyakarta.

Saran kedepannya, riset ini sebaiknya:

1. Menggunakan populasi yang berbeda dan penambahan instrumen penelitian untuk mengatahui konsistensi hasil penelitian mengenai budgetary slack.

2. Melakukan penambahan variable yang dominan mempengaruhi timbulnya budgetary slack.

3. Penggunaan metode pengumpulan data dengan melakukan kombinasi kuesioner dan dibuktikan dengan melakukan observasi serta wawancara.

\section{DAFTAR PUSTAKA}

Ana, M., \& Ratnadi, N. (2016). Pengaruh Partisipasi Penganggaran Pada

Kesenjangan Anggaran Dengan

Ambiguitas Peran Sebagai Variabel

Pemoderasi. E-Jurnal Akuntansi, 16(1), 781-811.

Anggasta, E. G., \& Murtini, H. (2014).

Informasi Sebagai Pemoderasi ( Studi

Pada SKPD Kota Semarang ).

Accounting Analysis Journal, 3(4), 513523.

http://journal.unnes.ac.id/sju/index.php/a aj

Anthony, N. R. \& G. (2011). Sistem Pengendalian Manajemen. Tangerang.

Ardila, L. (2013). Pengaruh Partisipasi

Anggaran Terhadap Senjangan Anggaran

Dengan Ambiguitas Peran dan Asimetri

Informasi Sebagai Pemoderasi. Jurnal

Akuntansi, 1(1), 2-17.

Bangun, N., \& Andani, K. W. (2012).

Pengaruh Budgetary Participation,

Information Asymmetry, Budget

Emphasis, dan Self Esteem Terhadap

Budgetary Slack. In Jurnal Akuntansi

(Vol. 12, Issue 1, pp. 577-594).

Basyir, A. A. (2016). Pengaruh Partisipasi

Anggaran, Informasi Asimetri, dan

Kapasitas Individu Terhadap Budgetary

Slack Pada SKPD Pemerintah Kota 
Samarinda. 13(2), 82-102.

Dianthi, I. A. G. P., \& Wirakusuma, M. G. (2017). Pengaruh Partisipasi Penganggaran, Asimetri Informasi, Budaya Organisasi Dan Komitmen Organisasi Pada Senjangan Anggaran. EJurnal Akuntansi Universitas Udayana ISSN : 2302-8556, 18(Vol.18.2), 874901.

Dunk, A. S. (1993). The Effect of Budget Emphasis and Information Asymmetry on the Relation between Budgetary Participation and Slack. The Accounting Review, Vol. 68, N, 400-410. https://www.jstor.org/stable/248408

Fadhli, A., \& Indriani, M. (2019). Pengaruh Budget Emphasis, Partisipasi Anggaran , Keterlibatan Pekerjaan, Dan Locus of Control Terhadap Kesenjangan. Jurnal Ilmiah Mahasiswa Ekonomi Akuntansi (JIMEKA), 4(1), 13-22.

Fanani, Z., \& Saudale, G. E. K. (2019). Influence of Information Asymmetry and Self-Efficacy on Budgetary Slack: An Experimental Study. Jurnal Akuntansi Dan Keuangan, 20(2), 62. https://doi.org/10.9744/jak.20.2.62-72

Gusti, J. S., \& Sofyan, E. (2019). Pengaruh Tekanan Anggaran, Ambiguitas Peran, Opportunistic Behaviour, dan Self Esteem terhadap Budgetary Slack. Jurnal Eksplorasi Akuntansi, 1(3), 14941509.

http://jea.ppj.unp.ac.id/index.php/jea/issu e/view/13

Hansen, D. R., \& Mowen, M. M. (2009). Accounting Managerial. In Buku 1 Edisi 8. Singapore: Cengage Learning.

Horngren, C. T., Sundem, G. L., \& David Burgstahler, And Schatzberg, J. (2014). Pengantar Akuntansi Manajemen. Jakarta: Erlangga.

Jermias, J., \& Yigit, F. (2013). Budgetary participation in Turkey: The effects of information asymmetry, goal commitment, and role ambiguity on job satisfaction and performance. Journal of International Accounting Research, 12(1), 29-54.

https://doi.org/10.2308/jiar-50385

Judge, T. A., \& Robbins, S. P. (2015).
Perilaku Organisasi Organizational Behavior. In Edisi 16 (p. 600). Jakarta: Salemba Empat.

Kung, F. H., Huang, C. L., \& Cheng, C. L. (2013). An examination of the relationships among budget emphasis, budget planning models and performance. Management Decision, 51(1), 120-140.

https://doi.org/10.1108/00251741311291 346

Kusniawati, H., \& Lahaya, I. A. (2018). Pengaruh Partisipasi Anggaran, Penekanan Anggaran, Asimetri Informasi terhadap Budgetary Slack pada SKPD Kota Samarinda. Akuntabel, 14(2), 144.

https://doi.org/10.29264/jakt.v14i2.1904

Lubis, A. I. (2017). Akuntansi Keperilakuan. In Edisi 3 (p. 778). Jakarta: Salemba Empat.

Mukaromah, A., \& Suryandari, D. (2015). Pengaruh Partisipasi Anggaran, Asimetri Informasi, Komitmen Organisasi, Ambiguitas Peran Terhadap Budgetary Slack. 4(4), 1-8.

Panjaitan, F. B., Margaret, R., \& Carolina, Y. (2019). Faktor-Faktor yang Mempengaruhi Budgetary Slack pada Dinas Pengelolaan Keuangan dan Aset Daerah di Propinsi Jawa Barat. Journal of Accounting, Finance, Taxation, and Auditing, 1, 75-90.

http://journal.maranatha.edu/jafta

Putra, I. G. E. D., \& Mintoyuwono, D. (2019). Pengaruh Partisipasi Anggaran, Penekanan Anggaran, Dan Komitmen Organisasi Terhadap Senjangan Anggaran Pada Suku Dinas Pemerintahan Di Dki Jakarta. Equity, 20(2), 59. https://doi.org/10.34209/equ.v20i2.625

Rahajeng, A. (2016). Perencanaan Penganggaran Keuangan Daerah. Yogyakarta: Gadjah Mada University Press.

Rifqi, R. A., Subekti, I., \& Rahman, A. F. (2017). The Effect of Budget Participation to Budgetary Slack With External Pressure as Moderating Variable. Journal of Accounting and 
Business Education, 1(1), 178.

https://doi.org/10.26675/jabe.v1i1.9757

Robbins, S. P., \& Judge, T. A. (2017).

Perilaku Organisasi. Jakarta: Salemba

Empat.

Savitri, E., \& Sawitri, E. (2014). Pengaruh

Partisipasi Anggaran, Penekanan

Anggaran, dan Informasi Asimetri

Terhadap Timbulny Kesenjangan

Anggaran. Jurnal Akuntansi, 2(2), 210226.

Selly Oberty Dany Adana Putri, Dwiati

Marsiwi, I. F. U. (2012). Jurnal ekonomi, manajemen dan akuntansi. Penekanan

Anggaran, Kapasitas Individu Dan

Group Cohesiviness Terhadap

Kecenerungan Menciptakan Budgetary

Slack Pada Organisasi Sektor Publik, 18(1), 56-66.

Suartana, I. W. (2010). Akuntansi

Keperilakuan Teori dan Implementasi.

Yogyakarta: ANDI.

Tenriwaru. (2015). Pengaruh Partisipasi

Anggaran, Asimetri Informasi, dan

Penekanan Anggaran terhadap

Kesenjangan Anggaran Pemerintah

Kabupaten Wajo. Assets, 5(1), 129-141.

http://id.portalgaruda.org/?ref=browse \&

$\bmod =$ viewarticle $\&$ article $=445864$

Undang-Undang Republik Indonesia Nomor

23 Tahun 2014 tentang Pemerintahan

Daerah. (n.d.).

Yeandrawita, Rasuli, M., \& Safitri, D. (2015).

Pengaruh Partisipasi Anggaran,

Informasi Asimetri, Kompleksitas Tugas

dan Penekanan Anggaran terhadap

Senjangan Anggaran pada Instansi

Pemerintah Daerah (Survei pada Skpd

Pemerintah Kabupaten Bengkalis).

Jurnal Online Mahasiswa Fakultas

Ekonomi Universitas Riau, 2(2). 